\title{
Gender Dysphoria in the Pediatric Population: Initial Experience of a Transdisciplinary Group
}

\section{Disforia de género en la población pediátrica: experiencia inicial de un grupo transdisciplinario}

\author{
Catalina Forero ${ }^{3}$ Nicolas Fernandez ${ }^{4}$ () \\ ${ }^{1}$ Division of Urology, Hospital Universitario San Ignacio, Pontificia \\ Universidad Javeriana, Bogotá, D.C, Colombia \\ 2 Urology Department, Fundación Santa Fe de Bogotá, Universidad de \\ los Andes, Bogotá, D.C, Colombia \\ 3 Pediatric Endocrinology Division, Hospital Universitario San Ignacio, \\ Pontificia Universidad Javeriana. Bogotá, D.C, Colombia \\ ${ }^{4}$ Division of Urology, Seattle Children's Hospital, University of \\ Washington, Seattle, WA, United States
}

Camila Moreno-Bencardino ${ }^{1}$ Laura Zuluaga ${ }^{2}$ Jaime Perez $^{1,2}$ Camila Cespedes $^{3(0)}$

\begin{abstract}
Address for correspondence Nicolas Fernandez, M.D., PhD, Seattle Children's Hospital University of Washington, 4800 Sand Point Way NE, Seattle, WA 98105, USA (e-mail: Nicolas.fernandez@seattlechildrens.org).
\end{abstract}

Urol Colomb 2021;30(4):e286-e292.

\begin{abstract}
Keywords

- gender dysphoria

- pediatric

- adolescent

- transdisciplinary

Introduction Although there is an increasing experience in the management of transgender individuals, this has not been thoroughly explored in children. The need to establish a comprehensive and transdisciplinary management is of critical importance. In order to solve this issue, we want to report the results of a cohort of individuals with gender dysphoria (GD) seen by our transdisciplinary group from a social and clinical and health access perspective.

Methods A 10-year retrospective case series of all patients that had been seen by our transdisciplinary team was reviewed. The main demographic characteristics were described, as well as impact variables in terms of diagnosis and treatment of these individuals. A social description of each individual was described. Frequency, distribution, and central tendency measures were evaluated for data presentation. IBM SPSS Statistics for Windows, version 24.0 (IBM Corp, Armonk, NY) software was used.

Results Four cases of GD were included. Three had male to female dysphoria and one female to male. The median reported age of GD awareness was 6 years old (between 4 and 8 years old), and the median time between GD awareness and the $1^{\text {st }}$ medical evaluation was 7 years for all individuals. The median age at gender role expression was 12 years old (between 10 and 14 years old). All patients had already assumed their experienced gender role before the $1^{\text {st }}$ evaluation by our group. The median age at the $1^{\text {st }}$ evaluation by our group was 13 years old (between 10 and 16 years old); three of the patients were evaluated after initiation of puberty. In the present study, individuals with GD demonstrated having health care access barriers for their transition process.
\end{abstract}

received

August 31, 2020

accepted

December 22, 2020
DOI https://doi.org/

$10.1055 / \mathrm{s}-0041-1730327$.

ISSN 0120-789X.

e ISSN 2027-0119. (c) 2021. Sociedad Colombiana de Urología. All rights reserved. This is an open access article published by Thieme under the terms of the Creative Commons Attribution-NonDerivative-NonCommercial-License, permitting copying and reproduction so long as the original work is given appropriate credit. Contents may not be used for commercial purposes, or adapted, remixed, transformed or built upon. (https://creativecommons.org/ licenses/by-nc-nd/4.0/)

Thieme Revinter Publicações Ltda., Rua do Matoso 170, Rio de Janeiro, RJ, CEP 20270-135, Brazil 


\section{Resumen}

Palabras clave

- disforia de género

- pediatría

- adolescentes

- grupo transdisciplinario
Referral times are high, and individuals with GD are cared after pubertal development, which is related to suboptimal outcomes. The spectrum of GD is broad, and management must be individualized according to expectations.

Conclusion Individuals with GD face multiple access barriers that limit their possibility of being seen by a transdisciplinary team. This reflects in longer waiting times that negatively impact medical management. Gender dysphoria is a wide spectrum, and individuals should be evaluated individually by a transdisciplinary team.

Introducción En las ultimas décadas se ha ganado más experiencia en el manejo de individuos con disforia de genero (DG). Sin embargo, en la población pediátrica esto aun no se ha explorado completamente. La necesidad de ofrecer un manejo cuidadoso y transdisciplinario es de gran importancia. El objetivo de este estudio es presentar la experiencia de nuestro grupo transdisciplinario (GT) en el abordaje de pacientes con DG desde el punto de vista medico y social.

Materiales y métodos Se realizó un análisis descriptivo de los casos de DG en menores de 18 años tratados en los últimos 10 años por el GT de Desórdenes del Desarrollo e Identidad Sexual. Se usaron medidas de frecuencia y tendencia central para la presentación de datos mediante el programa SPSS, versión 24.0. Se realizó un análisis descriptivo de las variables: familia y dinámica social; evaluación psiquiátrica; expectativas; barreras de acceso; y abordaje del GT.

Resultados Se presentan cuatro casos de DG, tres hombre-mujer y uno mujerhombre. La edad a la primera sensación de disforia (PSD) fue en promedio 5,7 años, y el tiempo medio entre la PSD y la primera evaluación médica (PEM) fue de 6,25 años. La edad promedio a la primera evaluación por el grupo (PEG) fue de 13,25 años; 3 individuos tenían pubertad avanzada y 1 , incipiente. Dos individuos habían recibido atención médica antes de la PEG. Se identificó que, al momento de la valoración por el grupo, los individuos contaban con el apoyo de sus familiares, y el entorno escolar era cada vez más incluyente; en ninguno se identificó enfermedad psiquiátrica, y a todos se indicó acompañamiento por psicoterapia. La expectativa con el proceso fue heterogénea con respecto a procedimientos quirúrgicos, manejos hormonales y rol de género, dependiendo de las características físicas que generaban disforia (caracteres sexuales secundarios, genitales). Las barreras de acceso fueron el desconocimiento de los especialistas en primeras valoraciones y las administrativas. La decisión del grupo con respecto al manejo hormonal y quirúrgico, así como acompañamiento psicológico se individualizó para cada paciente.

Conclusiones Los individuos con DG presentan barreras de acceso a soporte médico para su proceso de transición. Los tiempos de atención son prolongados; por ende, son atendidos después de desarrollar la pubertad, lo cual se relaciona con desenlaces subóptimos. El espectro de la DG es amplio y se debe individualizar el manejo según las expectativas.

\section{Introduction}

For the last few decades, considerable progress in gender dysphoria (GD) terminology and understanding about its management has been achieved. The World Professional Association for Transgender Health (WPATH) has promoted the standard of care for transgender individuals. ${ }^{1}$ Social acceptance and awareness is increasing, resulting in a higher number of children and adolescents supported by their families, who are now seeking medical support and management. ${ }^{2}$

However, there are still many areas of uncertainty with a lack of standardized and accepted protocols for a proper approach and management of these individuals, especially in the pediatric population. ${ }^{3,4}$ This is secondary to several barriers for managing children and adolescents with GD. These barriers are: lack of standardized terminology, lines of treatment, long-term surgical options, legal limitations, and 
scarce information and publications in this age range, with unknown long-term effects. ${ }^{5-9}$

Furthermore, management of these individuals with a transdisciplinary group is of critical importance in order to ensure optimal outcomes. ${ }^{10,11}$ Our $>10$-year experience as a transdisciplinary group treating disorders of sex development (DSD) has now started to get an increasing number of new referrals of GD children and adolescents. ${ }^{12}$ Although two completely different situations, we have decided to implement internal protocols to manage GD individuals with the same transdisciplinary approach as the one for DSD patients.

Here, we want to present a case series study and the experience of managing GD individuals, their families and social environments with our transdisciplinary group.

\section{Methods}

After Institutional Review Board (IRB) approval, we performed a retrospective chart review of all GD cases in the pediatric population (individuals $<18$ years old) evaluated at our transdisciplinary group at the Hospital Universitario San Ignacio San Ignacio, composed by pediatric endocrinology, pediatric and reconstructive urology, psychiatry, psychology, genetics, and social work specialists.

The included patients were all those seen within the last 10 years. All included individuals should have been presented and discussed at the monthly transdisciplinary meeting of Developmental Disorders and Sexual Identity in order to be enrolled for analysis. ${ }^{12}$ Given the lack of international agreement on current available terminology, we followed the self-perception of the patient as the primary diagnostic criteria. ${ }^{13}$ Taking these criteria into account, a review of the medical records and database of the group was carried out to determine which individuals should be included and the necessary information. Approval was obtained by the institutional ethics committee.

The variables that were determined for the presentation of the cases were: age at the time of assessment by the group, biological gender (male or female), gender identity (male or female), age at the first sensation of GD, age at the first expression of gender role (with which the patient is identified), age at the first medical evaluation (FME), time between the first sensation of gender dysphoria and the first medical evaluation, age at the first evaluation by the group (FGE), whether this consultation was before or after puberty; the time between the FME and the FGE (time to referral in months), whether they had received treatments before the FGE, adherence to those treatments, physical examination at the time of the FGE (Tanner classification), ${ }^{14}$ if they had any psychiatric diagnosis at the time of the FGE, and the followup time in months after the FGE. All ages and time intervals are reported in years, unless otherwise specified.

The following variables were reported according to the findings of the interdisciplinary group analysis: type of dysphoria ("male to female" or "female to male"), social and family dynamics, psychiatric assessment, expectations of the individual with the process of affirming gender, access barriers, and approaching the group. If there was missing data, a telephone follow-up was made to collect the pending information.

Frequency, distribution, and central tendency measures were evaluated for the presentation of data. IBM SPSS Statistics for Windows, version 24.0 (IBM Corp, Armonk, NY) software was used.

\section{Results}

During the study period, we identified four cases of GD individuals that had been evaluated by our group. Three had male to female dysphoria and one female to male. The median reported age of GD awareness was 6 years old (between 4 and 8 years old), and the median time between GD awareness and the FME was 7 years for all individuals. The median age at gender role expression was 12 years old (between 10 and 14 years old). All patients had already assumed their experienced gender role before the FGE. The median age at the FGE was 13 years old (between 10 and 16 years old); 3 of the patients were evaluated after initiation of puberty, and 3 of them were Tanner 4 at the FME and 1 was Tanner 2. Two patients had evaluation of their GD prior to the transdisciplinary assessment at our institution, and one of them had already started medical management (- Table 1. See attachment 1 ). The description of the cases can be found in -Table 2.

\section{Discussion}

Gender dysphoria constitutes a common underreported condition. It is characterized by being a multidimensional phenomenon that is expressed on a very subjective way. Given the variability in terminology, it is difficult to define an accurate prevalence. It has been reported to occur in between $\sim 0.17$ and $1.3 \%$ of adolescents and young adults. ${ }^{2}$ For GD individuals, their biological gender and their gender identity (or experienced gender) do not match each other, which is translated in nonconformity and distress. ${ }^{3,15,16}$

The diagnosis of GD in childhood and adolescence is a challenge. The classical diagnostic criteria accepted by the Diagnostic and Statistics Manual of Mental Disorders, 5th edition (DSM-V) are mainly gender incongruence, displayed as the decision to express their experienced gender role early in their lives, as well as dislike for their sexual anatomy and the desire for the sexual characteristics of the "other" gender. However, the term "diagnosis" must only be used for the purpose of allowing medical access to hormonal treatments and surgical interventions, but it should not be misconstrued. $^{6}$

All individuals in our case series expressed awareness of their self-perception and incongruence with their biological gender at an early age. However, the mean time between GD awareness and the FME was 6 years, which means that first time these individuals seek medical support is around the time they begin puberty. Furthermore, the first evaluation by a transdisciplinary group occurred even later, which is why all the individuals were Tanner 4 at the moment of the 


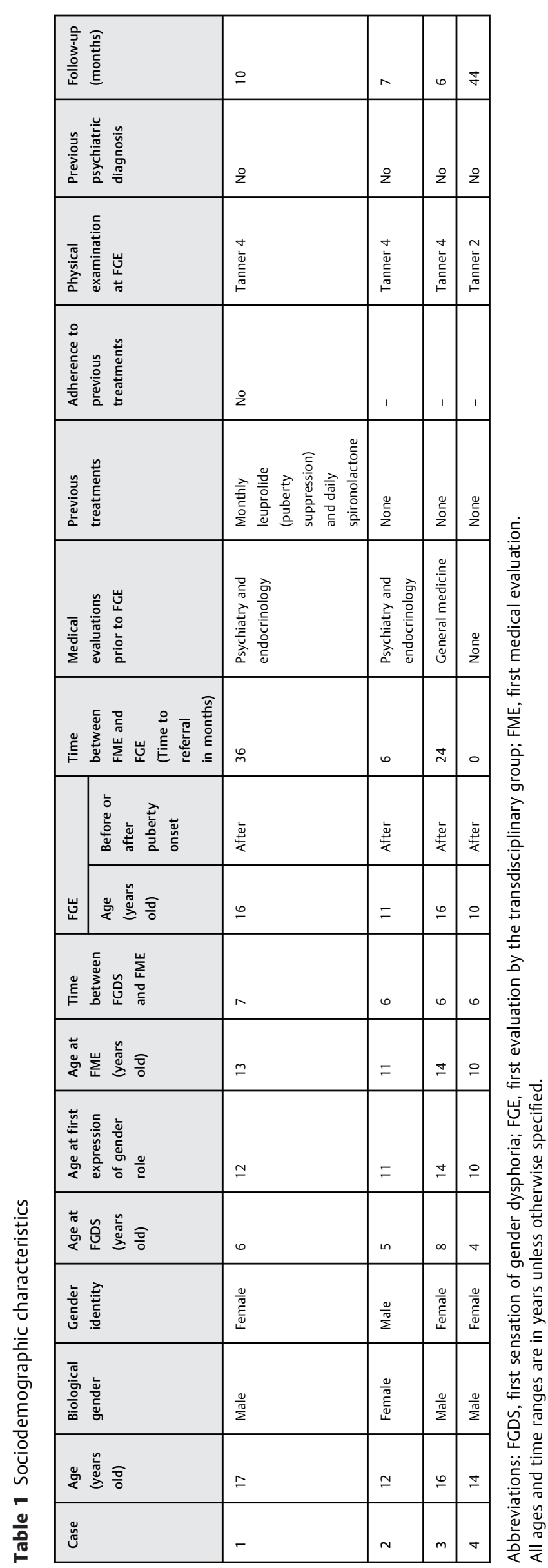

evaluation by the group, except for one. This finding is of utmost relevance, because most evidence suggests that early hormonal therapy and prevention of "wrong puberty" are the mainstay for the approach of GD children and adolescents. A study of 55 young transgender adults who received proper and early evaluation and were treated with puberty suppression, cross-sex hormones, and gender affirmation surgery at mean ages of 13.6, 16.7 and 20.7 years old, respectively, demonstrated that GD was alleviated and that psychological functioning improved, with results similar or even better than those of same-age young adults from the general population. ${ }^{17}$

Remarkably, most information is obtained and adapted from adult series, which may not rightfully represent the experiences of children and adolescents. It also includes the bias of someone who did not have the opportunity to be treated and supported accordingly. Due to different legislations that prevent them from making decisions before the legal age of adulthood, as well as a discriminating social context, many adult individuals have been exposed to rejection and discrimination, and experience gender affirmation processes on their own, without any psychological or endocrinological support. Also, some are identified due to a history of psychopathological comorbidity, such as substance abuse, depression, anxiety or suicide attempts. ${ }^{3,10,15,18,19}$ Early treatment and social and family support may reduce these situations. In our case series, none of the individuals have been diagnosed with any psychiatric disorders. However, in three of them, being already Tanner 4 at the FGE, high rates of distress and anxiety regarding their secondary sexual characteristics and the irreversibility of them are described. Consequently, their main expectation with the process is to surgically remove them.

Early intervention, including prepubertal early hormonal therapy and social and medical support, may have an impact on the desire for gender affirmation surgeries. This suggests that in an appropriately accompanied gender affirmation process, individuals may have better acceptance of their selfperception and their goal would not necessarily be the complete gender affirmation surgery, which again refers to the wide spectrum of GD. It is also important to consider that these individuals who start earlier usually have a supportive social environment, which lessens the impact of discrimination and, once more, could intercede in the vision they have of their own bodies and in the need of additional interventions. This relationship between the start of treatment and surgical need should be studied in future research. Given the scarce information available about hormonal management and long-term implications, we as a group have implemented some preventive follow-up measures, such as bone health evaluation after hormonal treatment has started. Better and more robust follow-up protocols evaluating long-term hormonal therapy implications will need to focus on bone as well as on cardiovascular health. ${ }^{20}$

Another finding is the variability in the manifestations of GD. It is remarkable how the second individual only felt dysphoria for his breasts and menstruation as the external manifestations of his phenotypic gender, but not for the 


\begin{tabular}{|c|c|c|c|c|}
\hline & 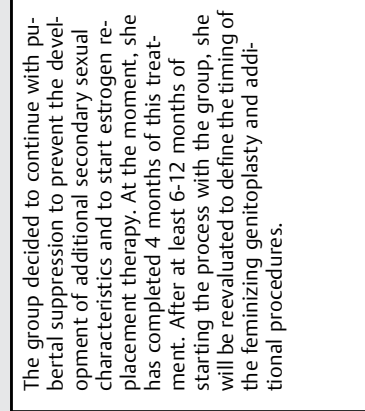 & 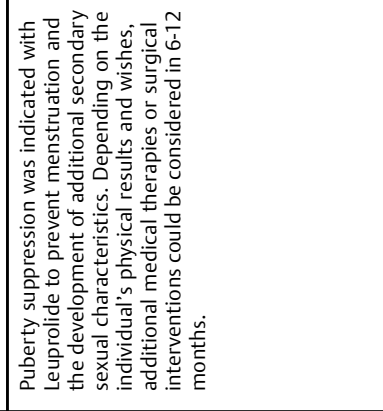 & 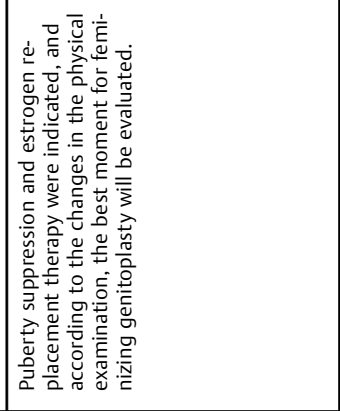 & 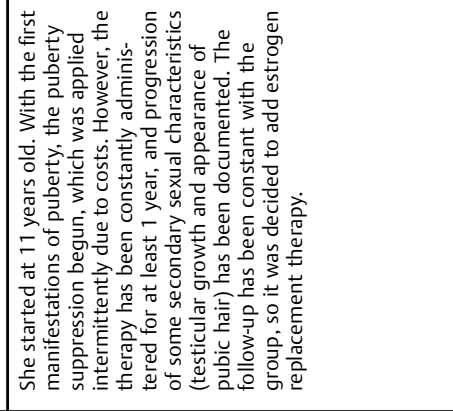 \\
\hline & 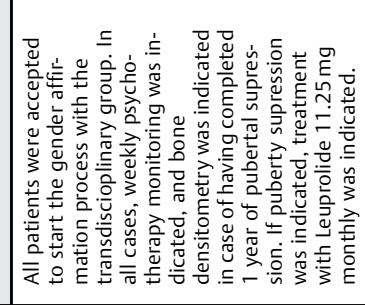 & & & \\
\hline & 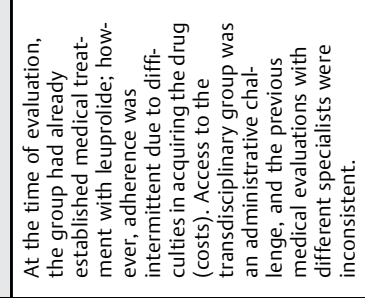 & 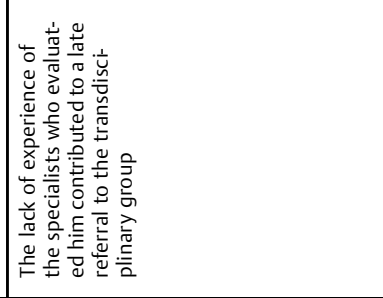 & 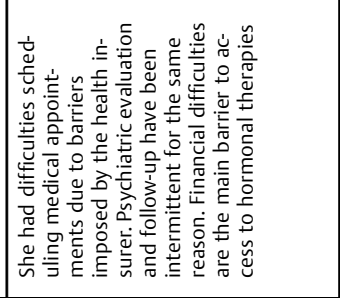 & 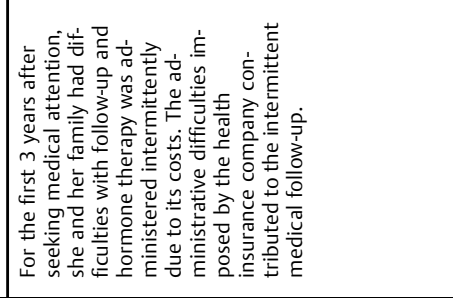 \\
\hline & 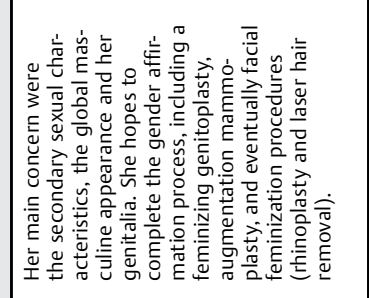 & 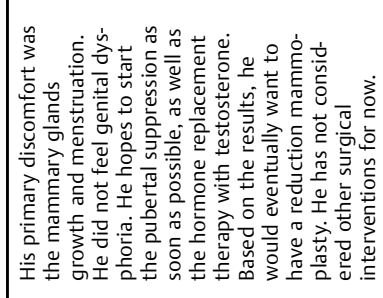 & 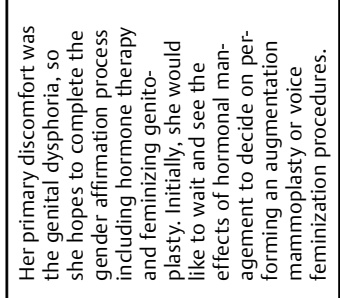 & 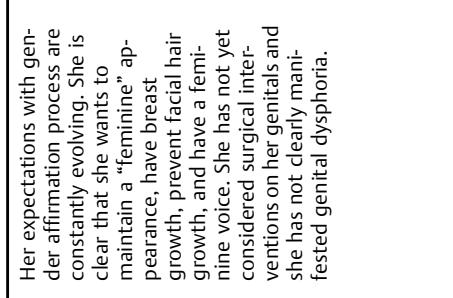 \\
\hline & 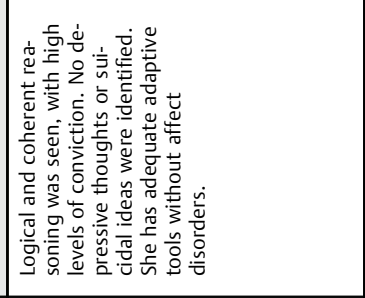 & 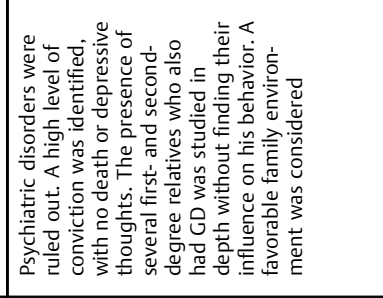 & 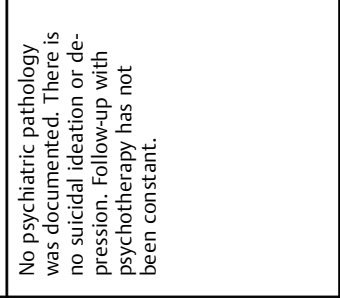 & 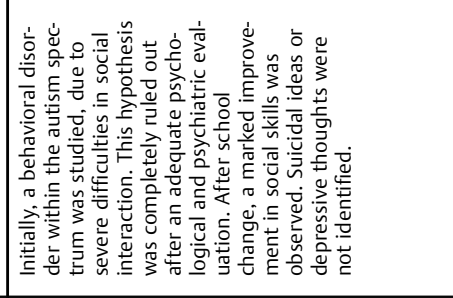 \\
\hline 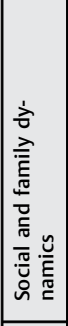 & 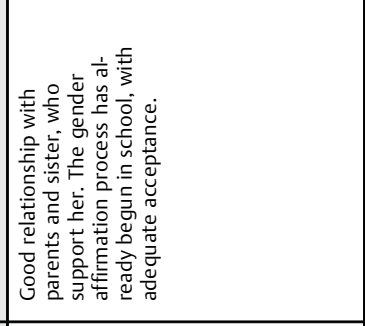 & 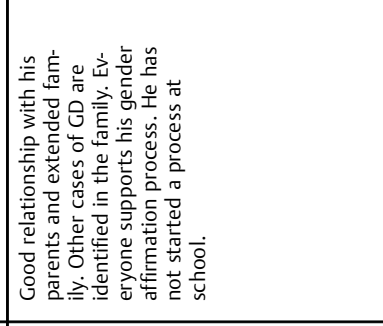 & 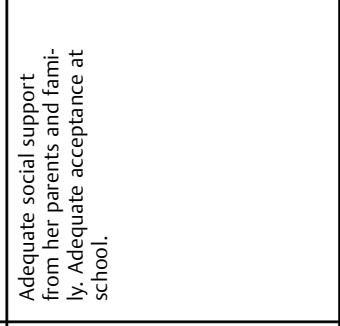 & 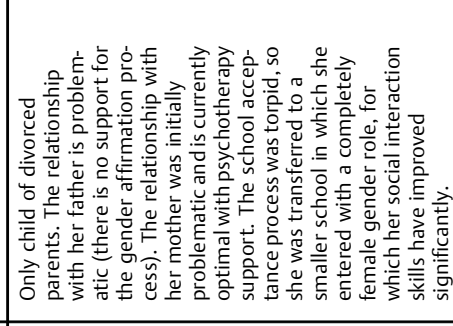 \\
\hline 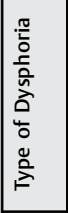 & 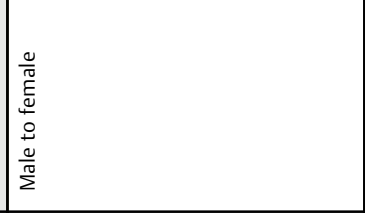 & 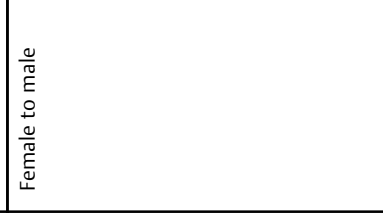 & 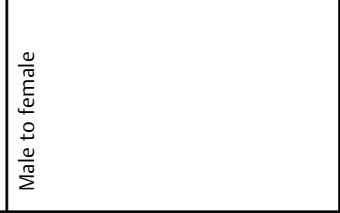 & 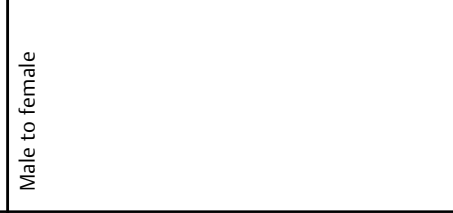 \\
\hline 气ّ̊ & - & N & m & - \\
\hline
\end{tabular}

Revista Urología Colombiana / Colombian Urology Journal Vol. 30 No. 4/2021 @ 2021. Sociedad Colombiana de Urología. All rights reserved. 
actual genitalia. This means that, probably, surgical affirming interventions should be individualized and directed to the needs of each individual. As has been widely described, some people may identify as predominantly "male" or "female", but with aspects of the "other" gender, which is why there is a wide terminology to define a situation where neither "male" nor "female" is suitable - "gender fluid", "pangender", "bigender", "agender", "gender neutral”, or even "genderless". 5,21,22 However, all individuals in our case series were able to clearly define their gender identity as "male" or "female", therefore, more on a binary fashion, which is why we did not need to use any other terminology. We hypothesize that this binary self-appreciation may be influenced by their social perception of gender and their knowledge about it, which means we could not be sure if these gender identities could evolve or change within their gender affirmation processes, especially in the aforementioned individuals who did not clearly feel dysphoria for their genitalia.

Another topic of controversy is the best timing for hormonal intervention and definitive therapies, with the main concern being chronic secondary effects. Experts suggest a cautious attitude towards the moment of transition and that "[...] parents and caregivers should fully realize the unpredictability of their child's psychosexual outcome [...]"23. The World Professional Association for Transgender Health (WPATH) published guidelines (2001) and The Endocrine Society Guidelines for Transgender Care both classify the interventions and the optimal ages for them, as "fully reversible" for puberty suppression therapy, "partially reversible" for cross-sex hormones at the age of 16 years old, and "irreversible" for surgical interventions at the age of 18 years old. ${ }^{7}$ In our case series, only the fourth individual received adequately timed puberty suppression therapy with leuprolide acetate. Gonadotropin releasing hormone analogues (GnRHa) are the most frequently used for puberty suppression. There are no irreversible effects found to be associated with this medication yet, ${ }^{24}$ except for some suggested effects on bone mineral density. Nonetheless, there is no clarity about mid- and long-term effects and about how to screen the effects of children undergoing these therapies. ${ }^{9}$ In our group, the fourth individual, who has been receiving leuprolide for almost 2 years, has been ordered to take an annual dual-energy X-ray absorptiometry (DXA) scan, as well as the first case, who was in puberty suppression therapy previously. The other two cases are planned to undergo a DXA at 1 year from the initiation of therapy. Furthermore, regarding puberty suppression, we find important to highlight that three of our individuals were indicated to initiate puberty suppression at Tanner 4 stage. Even though the guidelines propose not to start suppression therapy in individuals $>16$ years old, Klaver et al. found that the age of initiation of GnRHa was $\sim 14.5 \pm 1.8$ years old. ${ }^{13}$ Furthermore, guidelines also mention that there is a lack of evidence and that the potential irreversibility of this treatment with little adverse effects is remarkable. ${ }^{8}$ Moreover, the Endocrine Society Guidelines argue that cross-sex hormones should not be initiated before the age of 16 years old, since there are scarce studies at ages between 13 and 14 years old, but there is controversial evidence about the best management protocol. ${ }^{8,25}$

It has been stated that, despite the clear guideline recommendations, the number of children and adolescents who are actually receiving the proposed treatments is lower than those who are appropriate candidates. ${ }^{26}$ Many of these individuals are unable to access treatment mainly due to insurance difficulties, social/geographical barriers, family dynamics, the high cost of medical treatments, and lack of insurance coverage; but also due to ignorance by part of physicians about the standard of care of these individuals and, finally, the limited number of centers who are currently offering integral treatment. This ultimately ends in a high number of children and adolescents who seek support late, after reaching Tanner 3 stage, making puberty suppression less effective. ${ }^{25,27}$ In our own experience, the same barriers previously described have been identified. The main limitation we found for our individuals is the difficulty in acquiring drug therapy due to its high costs, given that insurers do not provide the medications in this country. Also, some of them had previous intermittent and irregular evaluations by different specialists who did not refer them to a transdisciplinary group on time, finding a time frame between the FME ever and the FGE as long as 3 years, meaning that most of them had advanced puberty (but not complete) at the time of the FGE.

The Trans Youth Research Network group tried to reunite their patients in order to unify treatment. It includes 497 children and adolescents from 4 clinics in Los Angeles, Chicago, Boston, and San Francisco (United States of America), recommends the integral evaluation by endocrinology or adolescent medicine, nursing, psychiatry, psychology, and social work within the framework of a transdisciplinary group. However, the four centers all have a different psychological approach, use different types of puberty suppression medication and cross-sex hormones, have various times of initiation of treatments, as well as distinct monitoring schemes. $^{11}$

There are still many areas of uncertainty in the management of the pediatric GD population, and there are no clear guidelines that state the best management within the framework of a transdisciplinary group. However, it is clear that the opportune attention of patients in a coordinated group can improve psychosocial outcomes. $^{28}$

Our limitations as a study consist in the small number of cases and the short follow-up period, which results in impossibility to make statistical inferences from them. However, in our country, there is scarce information and publications regarding this topic, and the experience in the management of these patients is limited, which is why we consider of outmost importance to record our progress early in approaching these patients and to encourage other centers to create very much needed transdisciplinary groups, with the final purpose of helping these individuals overcome the described barriers. 


\section{Conclusion}

The management of GD children and adolescents is still an area of constant growth and development. Current recommendations are based in scarce information about the pediatric population. A transdisciplinary, coordinated, and early approach improves the psychosocial outcomes. It is frequent in our country to find the FME in the post-pubertal stage, in which the puberty suppression effect is limited; this is the biggest concern and challenge within our group. Social, economic, information and knowledge are the main barriers identified, and it should be the main objective of physicians to make an early identification and approach of GD children and to work in overcoming barriers to treatment.

Conflict of Interests

The authors have no conflict of interests to declare.

\section{References}

1 Olson J, Schrager SM, Belzer M, Simons LK, Clark LF. Baseline Physiologic and Psychosocial Characteristics of Transgender Youth Seeking Care for Gender Dysphoria. J Adolesc Health 2015;57(04):374-380

2 Skordis N, Kyriakou A, Dror S, Mushailov A, Nicolaides NC. Gender dysphoria in children and adolescents: an overview. Hormones (Athens) 2020;19(03):267-276

3 Panagiotakopoulos L. Transgender medicine - puberty suppression. Rev Endocr Metab Disord 2018;19(03):221-225

4 Safer JD, Tangpricha V. Care of Transgender Persons. N Engl J Med 2019;381(25):2451-2460http://www.ncbi.nlm.nih.gov/pubmed/ 31851801

5 Richards C, Bouman WP, Seal L, Barker MJ, Nieder TO, T'Sjoen G. Non-binary or genderqueer genders. Int Rev Psychiatry 2016;28 (01):95-102

6 American Psychiatric Association. DSM-5. Diagnostic and Statistical Manual of Mental Disorders. 5th ed. 2013

7 Coleman E, Bockting W, Botzer M, Cohen-Kettenis P, DeCuypere G, Feldman J, et al. Standards of Care for the Health of Transsexual, Transgender, and Gender-Nonconforming People, Version 7. https://doi.org/101080/1553273920117008732012;13(04): 165-232

8 Hembree WC, Cohen-Kettenis PT, Gooren L, et al. Endocrine treatment of gender-dysphoric/ gender-incongruent persons: An endocrine society clinical practice guideline. J Clin Endocrinol Metab 2017;102(11):3869-3903

9 Joseph T, Ting J, Butler G. The effect of GnRH analogue treatment on bone mineral density in young adolescents with gender dysphoria: findings from a large national cohort. J Pediatr Endocrinol Metab 2019;32(10):1077-1081

10 Edwards-Leeper L, Spack NP. Psychological evaluation and medical treatment of transgender youth in an interdisciplinary "Gender Management Service" (GeMS) in a major pediatric center. J Homosex 2012;59(03):321-336

11 Olson-Kennedy J, Chan Y-M, Rosenthal S, et al. Creating the Trans Youth Research Network: A Collaborative Research Endeavor. Transgend Health 2019;4(01):304-312
12 Fernandez N, Moreno O, Rojas A, et al. Manejo transdisciplinario de pacientes con desórdenes del desarrollo sexual en Colombia. Limitantes para un manejo oportuno e integral. Urol Colomb. 2017;26(03):164-168

13 Klaver M, de Mutsert R, Wiepjes C, Den Heijer M, Rotteveel J, Klink D. Hormonal treatment affects body composition and body shape in transgender adolescents. The Journal of Sexual Medicine 2018; 15:251-260

14 Emmanuel M, Bokor BR. Tanner Stages. The SAGE Encyclopedia of Lifespan Human Development SAGE Publications, Inc.; 2018

15 Martinerie L, Condat A, Bargiacchi A, Bremont-Weill C, de Vries MC, Hannema SE. MANAGEMENT OF ENDOCRINE DISEASE: Approach to the management of children and adolescents with Gender Dysphoria. Eur J Endocrinol 2018;179(05):R219-R237

16 Kaltiala-Heino R, Bergman H, Työläjärvi M, Frisén L. Gender dysphoria in adolescence: current perspectives. Adolesc Health Med Ther 2018;9:31-41

17 de Vries ALC, McGuire JK, Steensma TD, Wagenaar ECF, Doreleijers TAH, Cohen-Kettenis PT. Young adult psychological outcome after puberty suppression and gender reassignment. Pediatrics 2014; 134(04):696-704

18 Cole CM, O'Boyle M, Emory LE, Meyer WJ III. Comorbidity of gender dysphoria and other major psychiatric diagnoses. Arch Sex Behav 1997;26(01):13-26

19 Zucker KJ, Lawrence AA, Kreukels BPC. Gender Dysphoria in Adults. Annu Rev Clin Psychol 2016;12(01):217-247

20 Mahfouda S, Moore JK, Siafarikas A, et al. Gender-affirming hormones and surgery in transgender children and adolescents. Lancet Diabetes Endocrinol 2019;7(06):484-498

21 Lefevor GT, Boyd-Rogers CC, Sprague BM, Janis RA. Health disparities between genderqueer, transgender, and cisgender individuals: An extension of minority stress theory. J Couns Psychol 2019;66(04):385-395

22 Baldwin A, Dodge B, Schick VR, et al. Transgender and genderqueer individuals' experiences with health care providers: What's working, what's not, and where do we go from here? J Health Care Poor Underserved 2018;29(04):1300-1318

23 Steensma TD, Biemond R, de Boer F, Cohen-Kettenis PT. Desisting and persisting gender dysphoria after childhood: a qualitative follow-up study. Clin Child Psychol Psychiatry 2011;16(04): 499-516

24 Bonifacio JH, Maser C, Stadelman K, Palmert M. Management of gender dysphoria in adolescents in primary care. CMAJ 2019;191 (03):E69-E75

25 Butler G, De Graaf N, Wren B, Carmichael P. Assessment and support of children and adolescents with gender dysphoria. Arch Dis Child 2018;103(07):631-636

26 Shumer DE, Spack NP. Current management of gender identity disorder in childhood and adolescence: guidelines, barriers and areas of controversy. Curr Opin Endocrinol Diabetes Obes 2013;20 (01):69-73

27 Spack NP, Edwards-Leeper L, Feldman HA, et al. Children and adolescents with gender identity disorder referred to a pediatric medical center. Pediatrics 2012;129(03):418-425

28 Miller A, Davidson S. Co-ordinating meaning within a gender identity development service: What can the theory of the coordinated management of meaning offer clinicians working with young people, and their families, exploring their gender identities. Clin Child Psychol Psychiatry 2019;24(02):322-337 